\title{
Pengaruh Pemberian Sari Kacang Hijau Terhadap Kadar Hemoglobin Pada Ibu Hamil Di Puskesmas Sirnajaya Kecamatan Serang Baru Bekasi Tahun 2019
}

\author{
Risza Choirunissa*, Desima Resnawati Manurung \\ Fakultas Ilmu Kesehatan, Universitas Nasional, Jakarta, Indonesia \\ Corresponding author: Risza Choirunissa (risza.choirunissa@civitas.unas.ac.id) \\ Received: Mei, 20 2020; Accepted: June, 28 2020; Published: September, 12020
}

\begin{abstract}
ABSTRAK
Kejadian anemia kehamilan berkisar antara 20\% dan $89 \%$ dengan menetapkan $\mathrm{Hb} 11$ gr\% sebagai dasarnya. di kabupaten bekasi mengungkapkan bahwa anemia pada ibu hamil trimester ketiga sebesar $69 \%$ lebih besar dibandingkan dengan trimester kedua 31\%. Angka kejadian anemia di serang baru bekasi dalam kehamilan cukup tinggi (Dinas Kabupaten Bekasi 2018).Tujuan penelitian ini adalah untuk mengetahui pengaruh pemberian sari kacang hijau terhadap kadar hemoglobin pada ibu hamil di puskesmas sirnajaya kecamatan serang baru bekasi. Metode yang digunakan quasi-experiment dengan pendekatan pre-test and post-test with control design. Teknik sampling yang digunakan adalah Accendental sampling dengan jumlah sampel $30 \mathrm{ibu}$ hamil, 15 ibu hamil intervensi dan 15 kontrol dengan lembar observasi. Uji normalitas mengunakan Shapiro-Wilk, analisa menggunakan paired samples test dan uji pengaruh independent t- test. Hasil Penelitian menunjukan bahwa rata - rata kadar $\mathrm{Hb}$ pada kelompok intervensi sebelum diberikan sari kacang hijau 9,993 g/dl dan sesudah diberikan sari kacang hijau 11,287 g/dl, rata kadar Hb pada kelompok kontrol sebelum 9,780 g/dl dan sesudah $9,967 \mathrm{~g} / \mathrm{dl}$. Ada perbedaan terhadap kelompok intervensi uji paired sampel test yaitu sig $P$ value Sebesar $0,000<\alpha 0,05$. Sedangkan kelompok kontrol yang tidak diberikan sari kacang hijau Sebesar $0,036<\alpha 0,05$. Uji pengaruh kadar hemoglobin pada pemberian sari kacang hijau secara uji stastistik independent $\mathrm{T}$ Test didapatkan $P$ value sebesar $0,000<0,05$. Simpulannya yaitu Sari kacang hijau berpengaruh terhadap kenaikan kadar Hb. Diharapkan tenaga kesehatan dapat mengaplikasikan pemberian sari kacang hijau pada ibu hamil untuk meningkatkan kadar $\mathrm{Hb}$.
\end{abstract}

Kata Kunci: Pemberian Sari Kacang Hijau, Kadar Hemoglobin, Ibu Hamil

This is an open-acces article distributed under the terms of the Creative Commons Attribution-ShareAlike 4.0 International License.

\section{PENDAHULUAN}

Menurut WHO (World Health Organization), 20\% dari 515.000 kematian maternal di seluruh dunia disebabkan oleh anemia. Anemia merupakan masalah kesehatan masyarakat terbesar di dunia, terutama bagi kelompok Wanita Usia Subur (WUS) khususnya ibu hamil. Bagi ibu hamil, anemia berperan dalam peningkatan prevalensi kematian dan kesakitan ibu, dan bagi bayi dapat meningkatkan risiko kesakitan dan kematian bayi serta BBLR. Anemia 
umumnya terjadi di seluruh dunia, terutama di negara berkembang dan pada kelompok sosio ekonomi rendah. Secara keseluruhan anemia terjadi pada 5\% wanita di negara berkembang dan 3\% di negara maju (Departemen Gizi dan Kesmas UI, 2016). Hasil studi pendahuluan di Puskesmas Sirnajaya pada 12 ibu hamil diperoleh 58\% ibu hamil mengkonsumsi kacang hijau dalam bentuk bubur sebanyak 1 bulan sekali pada saat mengikuti kegiatan posyandu, dan 25\% ibu hamil mengkonsumsi kacang hijau dalam bentuk rempeyek dan sisanya tidak menyukai kacang hijau. Dari register pemeriksaan ibu hamil menunjukkan dari 12 orang ibu hamil dengan 4 ibu hamil mengalami anemia ringan dan 4 ibu hamil mengalami anemia sedang mengatakan bahwa selama ini ibu hanya mengkonsumsi tablet FE sesuai anjuran dari bidan, sedangkan pola makan selama ini hanya mengkonsumsi makanan berupa sayuran dan lauk yang sudah dimasak, sedangkan pemanfaatan kacang hijau hanya dikonsumsi ibu tidak rutin dalam bentuk bubur kacang hijau dan peyek kacang hijau.

\section{METODE}

Penelitian ini menggunakan desain penelitian quasy experimental dengan pendekatan pre-test and post-testwith control group design, eksperimen kuasi dengan membagi kelompok menjadi kelompok perlakuan dan kelompok kontrol, lalu kedua kelompok tersebut dilakukan pre-test sebelum ekperimen diberikan dan post-test sesudah eksperimen diberikan. Populasi adalah wilayah yang terdiri atas obyek/subyek yang mempunyai kualitas dan karakteristik tertentu yang ditetapkan oleh peneliti untuk dipelajari dan kemudian ditarik kesimpulannya (Sugiyono, 2014). Populasi dalam penelitian ini adalah ibu hamil Trimester I-III di Puskesmas Sirnajaya Kecamatan Serang baru bekasi dari bulan Oktober- Desember tahun 2019 yaitu sebanyak 60 orang yang lakukan pengecekan $\mathrm{Hb}$ dan di dapatkan ibu hamil yang anemia sebanyak 30 orang. Sampel adalah bagian dari populasi yang diteliti atau sebagian jumlah dari karakteristik yang dimiliki oleh populasi (Notoatmodjo, 2012). Metode pengambilan sampel dalam penelitian ini menggunakan teknik qouta sampling yaitu seluruh populasi dijadikan sampel semuanya yaitu sebanyak 30 orang. Sampel dalam penelitian ini dilakukan intervensi berupa pemberian Sari Kacang hijau sebanyak 30 Orang dibuat 2 kelompok yaitu 15 orang kelompok intervensi dan 15 orang kelompok kontrol.

\section{HASIL}

Tabel 1.1 Perbedaan Kadar Hemoglobin antara kelompok intervensi dan kontrol pemberian sari kacang hijau pada ibu hamil di puskesmas sirnajaya kecamatan serang baru bekasi 2019

\begin{tabular}{|c|c|c|c|c|c|}
\hline Hasil & $\mathbf{N}$ & Selisih & Mean & SD & $P$ value \\
\hline Kelompok Intervensi & 15 & -1294 & 9,993 & & 0,000 \\
\hline Sebelum & 15 & & 11,287 & 3701 & \\
\hline Sesudah & & & & & \\
\hline $\begin{array}{r}\text { Kelompok Kontrol Sebelum } \\
\text { Sesudah }\end{array}$ & $\begin{array}{l}15 \\
15\end{array}$ & -187 & $\begin{array}{l}9780 \\
9967\end{array}$ & 3114 & 0,036 \\
\hline
\end{tabular}

Berdasarkan uji paired t Test pada di atas, diketahui rata - rata kadar hemoglobin pada kelompok intervensi dari 9,993 naik sebesar (-1294) menjadi 11,287 . $P$ value $0,000(<\alpha$ 0,05) maka dapat disimpulkan bahwa ada perbedaan rata - rata kadar hemoglobin pada pemberian sari kacang hijau pada kelompok intervensi. Terdapat juga pada kelompok kontrol nilai rata - rata hemoglobin dari 9780 naik sebesar $(-187)$ menjadi 9967. $P$ value $0,036(<\alpha$ 0,05) maka dapat disimpulkan bahwa ada perbedaan rata - rata kadar hemoglobin pada pemberian sari kacang hijau pada kelompok kontrol. 
Tabel 1.2 Pengaruh kadar hemoglobin antara kelompok intervensi dan kontrol diberikan sari kacang hijau pada ibu hamil di puskesmas sirnajaya serang baru bekasi 2019

\begin{tabular}{ccccc}
\hline & \multicolumn{3}{c}{ Sari Kacang Hijau } & \\
\cline { 2 - 4 } Kelompok & $\mathrm{N}$ & Mean & $\mathrm{SD}$ & $P$ value \\
\hline Kontrol & 15 & 11,28 & 0,64 & \multirow{2}{*}{0,000} \\
Intervensi & 15 & 9,96 & 0,61 & \\
\hline
\end{tabular}

Berdasarkan uji indepent sampel test pada Tabel 1.2 di atas, diketahui hasil uji stastistik dapat dilihat dari $P$ value yaitu 0,000 yang artinya $\mathrm{p}<0,05$ yang artinya ada pengaruh sari kacang hijau terhadap kadar hemoglobin.

\section{PEMBAHASAN}

Berdasarkan uji paired t Test pada Table 1.1 di atas, diketahui rata - rata kadar hemoglobin pada kelompok intervensi dari 9,993 naik sebesar (-1294) menjadi 11,287. $P$ value $0,000(<\alpha 0,05)$ maka dapat disimpulkan bahwa ada perbedaan rata - rata kadar hemoglobin pada pemberian sari kacang hijau pada kelompok intervensi. Terdapat juga pada kelompok kontrol nilai rata - rata hemoglobin dari 9780 naik sebesar (-187) menjadi 9967. $P$ value $0,036(<\alpha 0,05)$ maka dapat disimpulkan bahwa ada perbedaan rata - rata kadar hemoglobin pada pemberian sari kacang hijau pada kelompok kontrol.

Manfaat kacang hijau selanjutnya ialah menjaga kesehatan tulang. Kandungan magnesium pada kacang hijau dipercaya bisa menurunkan risiko osteoporosis pascamenopause pada wanita dan bisa meningkatkan kepadatan tulang serta pembentukan sel-sel tulang.

Perlu diketahui, dalam 100 gram kacang hijau setidaknya ada 189 miligram magnesium. Jumlah ini tentu cukup agar dapat mencegah tubuh kekurangan magnesium. Saat Anda mengonsumsi magnesium dalam jumlah cukup, maka risiko osteoporosis yang anda derita akan berkurang.

Penelitian ini sejalan dengan penelitian Maulina (2010) juga menunjukkan pemberian kacang hijau selama 7 hari dapat meningkatkan kadar hemoglobin karena dalam hasil penelitiannya bahwa pemberian kacang hijau dosis $18 \mathrm{gr} / \mathrm{kg} \mathrm{BB} / \mathrm{hari}$ dan $36 \mathrm{gr} / \mathrm{kg} \mathrm{BB} / \mathrm{hari}$ efektif terhadap peningkatan kadar $\mathrm{Hb}$ pada tikus putih.

Pada wanita hamil dengan janin tunggal kebutuhan zat besi sekitar $1000 \mathrm{mg}$ selama hamil atau naik sekitar $200300 \%$. Perkiraan besarnya zat besi yang perlu ditimbun selama hamil 1040 mg. dari jumlah itu, $200 \mathrm{mg}$ zat besi tertahan oleh tubuh ketika melahirkan dan $840 \mathrm{mg}$ sisanya hilang. Sebanyak $300 \mathrm{mg}$ besi ditransfer ke janin dengan rincian 50-75 mg untuk pembentukan plasenta, $450 \mathrm{mg}$ untuk menambah jumlah sel darah merah dan $200 \mathrm{mg}$ hilang ketika melahirkan. Kebutuhan zat besi pada trimester pertama relatif lebih sedikit yaitu sekitar 0,8 mg per hari, tetapi pada trimester kedua dan trimester ketiga meningkat menjadi 6,3 mg per hari (Tarwoto \& Wasnidar, 2013), sedangkan menurut Saifudin (2006) kebutuhan ibu selama kehamilan ialah $800 \mathrm{mg}$ besi, diantaranya $300 \mathrm{mg}$ untuk janin plasenta dan $500 \mathrm{mg}$ untuk pertambahan eritrosit ibu, dengan demikian ibu membutuhkan tambahan sekitar 2-3 mg besi/hari, dan menurut Jordan (2004) ibu hamil sejak berusia 20 minggu memerlukan zat besi $65 \mathrm{mg}$ per hari.

Hasil penelitian ini sejalan dengan penelitian Dewi dengan judul Pengaruh pemberian tablet fe dan bubur jus kacang hijau terhadap kadar hemoglobin pada ibu hamil. Data penelitian diambil dengan lembar observasi dan hal ini dibuktikan dengan uji T-berpasangan yang menunjukkan $p$-value $=0.005(p<0,05)$ bahwa "ada pengaruh pemberian tablet Fe dan bubur jus kacang hijau terhadap kadar haemoglobin pada ibu hamil". Hasil penelitian ini sejalan dengan penelitian yang dilakukan oleh Amirul (2016) dengan judul "efektifitas minuman kacang hijau terdapat peningkatan kadar Hb". Hasil penelitian menujukan bahwa rata - rata 
kadar hemoglobin $(\mathrm{Hb})$ 9,6 $\mathrm{g} / \mathrm{dl}$ atau mengalami anemia ringan sebelum pemberian minuman kacang hijau, dan rata - rata kadar hemoglobin $(\mathrm{Hb})$ 10,6 g/dl atau tidak anemia setelah pemberian minuman kacang hijau. Ada pengaruh pemberian pemberian minuman kacang hijau terdapat peningkatan kadar hemoglobin $(\mathrm{Hb})$ dengan $\mathrm{p}=0,000$.

Menurut asumsi peneliti masalah kadar hemoglobin sangat berpengaruh terhadap ibu dan janin karena jika ibu yang memiliki kurang kadar hemoglobin akan bermasalah sehingga akan berpengaruh kepada janin dan mengakibat dampak resiko kehamilan. Sehingga untuk menghindari masalah diatas diperlukan langkah pencegahan untuk mengatasi kadar hemoglobin meningat. Salah satunya adalah dengan pemanfaatan kacang hijau terhadap peningkatan kadar $\mathrm{Hb}$ yang pada penelitian ini telah diolah menjadi sari kacang hijau dengan hasil penelitian adanya perbedaan peningkatan kadar hemoglobin. Berdasarkan uji indepent sampel test pada Tabel 1.2 di atas, diketahui hasil uji stastistik dapat dilihat dari $P$ value yaitu 0,000 yang artinya $p<0,05$ yang artinya ada pengaruh sari kacang hijau terhadap kadar hemoglobin.

Kacang hijau mengandung zat besi sebanyak 2,25 mg dalam setiap setengah cangkir kacang hijau. Kacang hijau juga mengandung fitat sebesar 2,19\%. Fitat dapat menghambat penyerapan zat besi sehingga dianjurkan untuk merendam kacang hijau sebelum mengolahnya. Pengolahan kacang hijau melalui perendaman sebelumnya bertujuan untuk memudahkan penyerapan zat besi yang diperlukan untuk maturasi selsel darah (Heltty, 2018)

Biji kacang hijau yang telah direbus atau diolah dan kemudian dikonsumsi mempunyai daya cerna yang tinggi dan rendah daya flatulensinya. Hemaglutinin dapat menggumpalkan sel darah merah dan bersifat toksik. Toksisitas hemaglutinin dapat dihancurkan melalui proses pemanasan pada suhu $100^{\circ} \mathrm{C}$. Asam fitat dapat membentuk kompleks dengan Fe atau unsurunsur mineral, terutama $\mathrm{Zn}, \mathrm{Mg}$, dan Ca menjadi bentuk yang tidak larut dan sulit diserap tubuh sehingga mengurangi ketersediannya dalam tubuh karena menjadi sangat sulit dicerna. Proses fermentasi dapat meningkatkan ketersediaan unsur besi bagi tubuh. Hal ini penting untuk mencegah anemia gizi besi. Kacang hijau juga mengandung vitamin $\mathrm{C}$ yang membantu dalam melakukan penyerapan fe dalam tubuh karena dapat merubah bentuk feri menjadi fero (Astawan, 2019).Analisis penelitian dilakukan dua kali, penelitian pertama dilakukan pemeriksaan laboratorium yaitu dengan cara mengecek kadar hemoglobin awal pada ibu hamil trimester III yang mengalami anemia untuk mengetahui kadar hemoglobin ibu. Setelah mengetahui hasil pemeriksaan terdapat responden mengalami anemia dengan kadar hemoglobin rendah. Sebelum diberikan bubur kacang hijau responden mengalami keluhan lemas, kulit pucat, sesak napas dan pusing. Setelah diberikan bubur kacang hijau selama 7 hari keadaan responden mulai membaik terlihat lebih segar, rasa pusing dan sesak nafas mulai berkurang. Menurut asumsi peneliti dengan kandungan zat besi terdapat pada sari kacang hijau dapat meningkatkan produksi hemoglobin yang meningkat. Sari kacang hijau sangat gampang di temukan dimana perdesaan atau di perkotaan.

\section{KESIMPULAN}

Ada perbedaan pemberian sari kacang hijau terhadap kadar hemoglobin pada kelompok intervensi dengan rata - rata peningkatan kadar Hemonglobin setelah diberikan sari kacang hijau secara uji stastistik Paired sampel T test yaitu sig (2-tailed) sebesar 0,000<0,05. Sedangkan kelompok kontrol yang tidak diberikan sari kacang hijau sebesar 0,036 < 0,05 Ada pengaruh kadar hemoglobin pada pemberian sari kacang hijau secara uji stastistik independent $\mathrm{T}$ Test didapatkan sig (2-tailed) sebesar $0,000<0,05$. Diharapkan tempat penelitian dapat meningkatkan penyuluhan tentang penggunaan sari kacang hijau sebagai pencegahan anemia pada ibu hamil 


\section{REFERENSI}

Alamaister, S. 2016 . Prinsip Dasar Ilmu Gizi. Jakarta : PT.Cramedia Pustaka Utama

Arisman, 2016. Gizi Dalam Daur Kehidupan. Jakarta: EGC.

Adriani, M dan Wirjatmadi, B. 2012.peranan gizi dalam siklus kehidupan.Jakarta: Kencana Prenada Media Group

Amirudin, R. 2017. Status Gizi Ibu Hamil. Jakarta : EGC

Astawan, M., 2009. Sehat Dengan Hidangan Kacang dan Biji-Bijian. Penebar Swadaya, Jakarta.

Departemen Gizi dan Kesehatan Masyarakat Universitas Indonesia. (2012). Gizi dan Kesehatan Masyarakat. Jakarta: Rajawali Pers.

Indonesia.2016

Fakulitas Kesehatan Masyarakat Universitas

Dinas Kesehatan Daerah Istimewa Bekasi, 2017. Profil Kesehatan Bekasi : Dinas Kesehatan Bekasi

Serang Baru. 2017. Profil Kesehatan Kabupaten Serang Baru Tahun 2017, Serang Baru : Dinas Kesehatan Serang Baru

Aritonang, E. 2015. Kebutuhan Gizi Ibu Hamil. Sumatra Utara : IPB Press

Gandasoebrata, R. 2014. Penuntun Laboratorium Klinik. Jakarta :Dian Karya

Huda, N., \& Febriyanti, E. (2016). Campuran Jus Kacang Hijau Dan Jambu Biji Terhadap Peningkatan Kadar Hemoglobin ( Hb ) Pada Pasien Kanker Yang Menjalani Kemoterapi. Injec, $1(1), 5$.

Hidayat, R. 2017. Rancangan Kuasi Eksperimen. Yogyakarta : Penelitian Ilmu Sosial Indonesia

Haryati, N. 2012. Buku Acuan Nasional Pelayanan Kesehatan Maternal dan Neonatal. Jakarta: Bumi Aksara

Indonesia DKR. Pedoman Pemantauan Wilayah Setempat Kesehatan Ibu dan Anak (PWSKIA). Jakarta; 2003

Kementrian Kesehatan, R. I. (2013). Riset kesehatan dasar (Riskesdas) 2013. Jakarta: Badan Penelitian dan Pengembangan Kesehatan .(2016). Profil Kesehatan Indonesia. Profil Kesehatan Provinsi Jawa

Barat. Indonesia (Kemenkes RI).(2013) Riset Kesehatan Dasar (Riskesdas). Jakarta : Kemenkes RI. 2016. Pendoman Interpretasi Data Klinik. Jakarta: Kementerian

Kesehatan

Kiswari, R 2014. Hematologi dan Transfusi. Jakarta : Penerbit Erlangga

Klein, S dan Thompson, F. 2015. Panduan Lengkap Kebidanan. YogYakarta : Pustaka Baru Press.

Maulina, N., \& Sitepu, I. P. (2015). Pengaruh Pemberian Kacang Hijau (Phaseolus radiatus) Terhadap Peningkatan Kadar Hemoglobin Tikus Putih (Rattus norvegicus) Jantan Galur Wistar. Jurnal Pendidikan Kimia, 7(2), 57-60

Mufdlilah. 2009. Panduan Asuhan Kebidanan Ibu Hamil. Yogyakarta: Nuha Medika.

Notoatmodjo, S. (2014). Metedologi Penelitian Kesehatan. Jakarta. PT Rineka Cipta. 2013. Promosi Kesehatan dan Perilaku Kesehatan. Jakarta: PT Rineka Cipta.

Nugroho, T dan Utama I.B. 2014. Masalah Kesehatan Reproduksi Wanita. Yogyakarta: Nuha Medika.

Pamungkas, A. R. (2017). Metodologi Riset Keperawatan (Trans Info). Jakarta.

Prawiroharjo, S. (2014). Ilmu Kebidanan Sarwono Prawiro Hardjo (PT Bina Pu). Jakarta.

Proverawati, A., \& Asfuah, S. (2009). Buku ajar gizi untuk kebidanan. Yogyakarta: Nuha Medika, 1 
Reni, D. . et al. (2018). Perbedaan perawatan tali pusat terbuka dan kasa kering dengan lama pelepasan tali pusat pada bayi baru lahir. Ilmiah Kesehatan Dan Aplikasinya, 6(2), 1-6.

Retnorini, D. L., Widatiningsih, S., \& Masini, M. (2017). Pengaruh Pemberian Tablet Fe Dan Sari Kacang Hijau Terhadap Kadar Hemoglobin Pada Ibu Hamil. Jurnal Kebidanan, 6(12), 8

Rochyati, P. 2011. Skrining Antenatal Pada Ibu Hamil, Pengenalan Faktor Risiko. Jakarta . Airlangga University Press

Susanti, Kumala MT. 2011 Farmakologi Kebidanan, Aplikasi dalam praktik kebidanan. Jakarta Trans Info Media (TIM)

Sulystiwati, A 2009. Asuhan Kebidanan pada Masa Kehamilan. Jakarta: trans info media

Sukarni. Kehamilan, Persalinan, Dan Nifas. Yogyakarta: Nuha Medika; 2013.

Simanjuntak, D. H., \& Sudaryati, E. (2015). Gizi pada Ibu Hamil dan Menyusui. Universitas Sumatera Utara,.

Saifudin. Buku Acuan Nasional Pelayanan Kesehatan Maternal dan Neonatal. Jakarta: Yayasan Bina Pustaka; 2009.

Widia, L., \& Putri, A. S. (2019). EFEKTIVITAS KONSUMSI SARI KACANG HIJAU (Vigna Radiate) TERHADAP KELANCARAN PRODUKSI ASI IBU NIFAS (Consumption Effectiveness Of Green Beans Extract (Vigna Radiate) For Smoothing Out Therelease Of Breast Milk In Postpartum). Jurnal Darul Azhar, 7(1), 23-30.

Wirawan, R 2011. Pemeriksaan Laboratorium Hematolog, Jakarta : Universitas Indonesia

World Health Organization (WHO), 2015. Trends In Maternal MorTality : 1999 to 2015. Switzerland. WHO

Wirjatmadi A . 2015. Pengantar Gizi Masyarkat. Jakarta : Kencana Prenada Media.

Yuviska, I. A., \& Armiyanti, L. (2019). Perbedaan Pemberian Jus Kacang Hijau Dan Jus Jambu Biji Merah Terhadap Peningkatan Kadar Haeomoglobin Pada Risma Di Desa Maja Kecamatan Kalianda Tahun 2018. Jurnal Kebidanan Malahayati, 5(1), 52-60. https://doi.org/10.33024/jkm.v5i1.914.

Zarianis. 2016. Esensial Anatomi dan Fisologi dalam Asuhan Maternitas. Jakarta: EGC. 